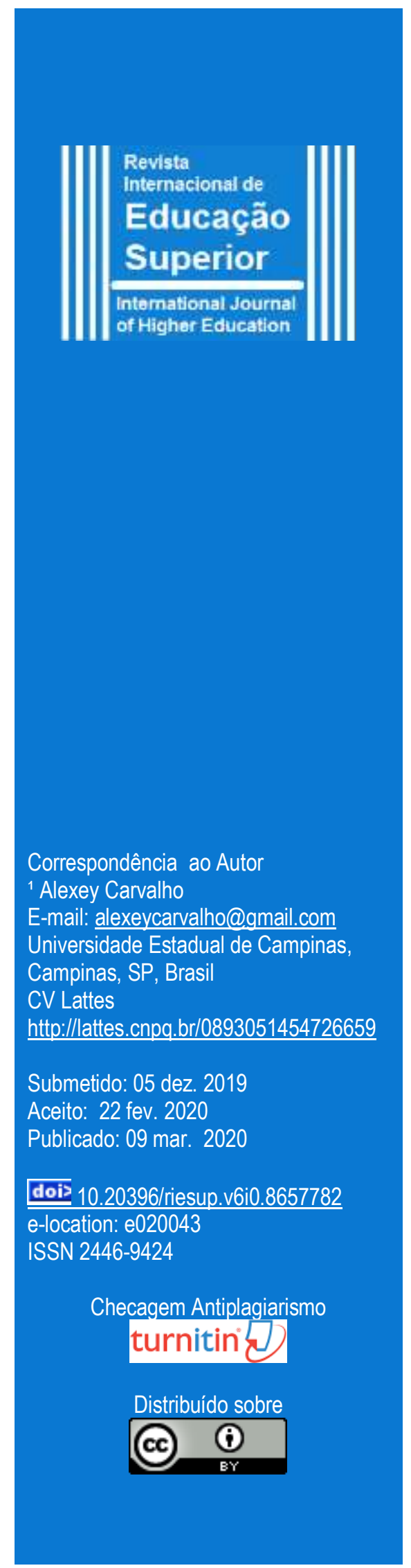

\title{
Avaliação e Acreditação da Educação Superior na América Latina e Caribe
}

Alexey Carvalho ${ }^{(}$(D) http://orcid.org/0000-0002-5100-1623

Maria Márcia Sigrist Malavasi (D) http://orcid.org/0000-0002-9144-4613

1,2 Universidade Estadual de Campinas

\section{RESUMO}

No contexto da América Latina e Caribe, há uma diversidade de Instituições de Educação Superior (IES) e de sistemas de avaliação e acreditação. Este artigo analisa alguns desses sistemas, buscando entender como se configuram, seus instrumentos de avaliação institucional e de cursos, seus estágios de maturidade, suas relações com as políticas públicas de seus respectivos países, bem como, aspectos relativos à valorização da autoavaliação e do contexto institucional. $O$ estudo se compõe de uma pesquisa bibliográfica e documental, tendo como base os documentos, legislações e informações oficiais dos organismos de avaliação e acreditação de cada país, além de uma pesquisa de campo, com professores e pesquisadores em atividade nessas localidades, no intuito de captar as percepções acerca desses sistemas em cada realidade. A pesquisa contou com respondentes de oito países: Brasil, Chile, Colômbia, Equador, México, Peru, Uruguai e Venezuela. Foi possível observar que apesar de haver uma grande diversidade e formatos de sistemas de avaliação e acreditação, há processos muito semelhantes em alguns deles, assim como ficou evidente um anseio dos respondentes no sentido de que os sistemas avancem para que haja uma contribuição efetiva na melhoria da qualidade. Os resultados da análise dos documentos e das percepções colhidas na pesquisa de campo, demonstraram que é preciso que os sistemas de avaliação e acreditação superem os aspectos burocráticos, de verificação de conformidade e busquem avaliações formativas, que valorizem a autoavaliação e a pertinência das IES e cursos, de forma a alimentar uma cultura de qualidade e melhoria contínua.

\section{PALAVRAS-CHAVE}

Educação superior. Avaliação. Acreditação. Política pública. 


\section{Higher Education Evaluation and Accreditation in Latin America and the Caribbean}

\section{ABSTRACT}

In the Latin American and Caribbean context, there are a variety of Higher Education Institutions (HEIs) and assessment and accreditation systems. This paper analyzes some of these systems, seeking to understand how they are configured, their institutional and course evaluation instruments, their stage of maturity, their relationship with the public policies of their country, as well as aspects related to the valuation of selfassessment and the institutional context. The study consists of a bibliographic and documentary research, based on the documents, laws and official information of the evaluation and accreditation bodies of each country, as well as a field research, with professors and researchers in activity in these locations, in order to capture the perceptions about these systems in each reality. The survey had respondents from eight countries: Brazil, Chile, Colombia, Ecuador, Mexico, Peru, Uruguay and Venezuela. It was observed that although there is a great diversity and formats of assessment and accreditation systems, there are very similar processes in some of them, as well as a desire of the respondents to see advance in the systems so that there is an effective contribution to the quality improvement. The results of the analysis of the documents and the perceptions gathered in the field research showed that the evaluation and accreditation systems need to overcome the bureaucratic aspects, compliance verification and to seek formative evaluations that value the self-evaluation and the pertinence of the HEIs and courses, to nurture a quality culture and continuous improvement.

\section{KEYWORDS}

Higher education. Evaluation. Accreditation. Public policy.

\section{Evaluación y Acreditación de la Educación Superior en América Latina y el Caribe}

\section{RESUMEN}

En el contexto de América Latina y el Caribe, hay una variedad de Instituciones de Educación Superior (IES) y sistemas de evaluación y acreditación. Este artículo analiza algunos de estos sistemas, buscando comprender cómo están configurados, sus instrumentos de evaluación institucional y de carreras, sus estados de madurez, sus relaciones con las políticas públicas de cada país, así como los aspectos relacionados con la valoración de la autoevaluación y el contexto institucional. El estudio consiste en una investigación bibliográfica y documental, basada en los documentos, leyes e informaciones oficiales de los organismos de evaluación y acreditación de cada país, así como una investigación de campo, con docentes e investigadores en actividad en estos lugares, con el fin de aprehender las percepciones sobre estos sistemas en cada realidad. La encuesta contó con encuestados de ocho países: Brasil, Chile, Colombia, Ecuador, México, Perú, Uruguay y Venezuela. Se observó que, aunque existe una gran diversidad y formatos de sistemas de evaluación y acreditación, hay procesos muy similares en algunos de ellos, así como el deseo de los encuestados de perfeccionar los sistemas para que se logre una efectiva mejora en la calidad. Los resultados del análisis de los documentos y las percepciones recogidas en la investigación de campo mostraron que los sistemas de evaluación y acreditación necesitan superar los aspectos burocráticos, la verificación del cumplimiento y buscar evaluaciones formativas que valoren la autoevaluación y la pertinencia de las IES y carreras para fomentar una cultura de calidad y mejora continua.

\section{PALABRAS CLAVE}

Educación superior. Evaluación. Acreditación. Política pública. 


\section{Introdução}

A região da América Latina e Caribe é marcada por sua grande diversidade cultural, social e étnica, além das diferenças de desenvolvimento econômico, as desigualdades sociais e a falta de uma educação de qualidade, presentes em alguns dos seus países.

Esse emaranhado sociocultural é refletido na Educação Superior e consequentemente em seus sistemas de avaliação a acreditação. Embora voltados à realidade de cada país, esses sistemas são impelidos a buscar a aplicação de métodos ou a utilização de indicadores de qualidade que visem uma comparação internacional. Destaca-se, de acordo com Carvalho (2018), que os organismos internacionais, dominados pelo grupo hegemônico das grandes economias, normalmente definem os conceitos, as diretrizes e orientações, com caráter supranacional, que devem ser seguidas pelos demais estados nacionais, muitas vezes negligenciando os aspectos culturais, de contextualização e de inserção social, indissociáveis do processo educativo e que podem não contribuir efetivamente para a melhoria da qualidade.

A Rede Ibero-americana para Acreditação da Qualidade da Educação Superior (RIACES, 2004, p.23, tradução nossa) define avaliação como sendo "processo para determinar o valor de algo e emitir um julgamento ou diagnóstico, analisando seus componentes, funções, processos, resultados para possíveis alterações de melhoria" e acreditação como "processo para garantir a qualidade de uma instituição, programa ou curso" (RIACES, 2004, p.9, tradução nossa). Assim, pode-se dizer que enquanto a acreditação tem ênfase no controle e na garantia da qualidade de uma forma mais ampla, a avaliação está relacionada ao processo em si, que poderá ou não garantir a qualidade. Ao longo desse artigo, são analisados os aspectos da avaliação, com vistas à acreditação.

Frequentemente há questionamentos acerca das avaliações externas de qualidade, do papel do Estado e da atuação dos organismos de avaliação e acreditação como garantidores da qualidade e promotores da melhoria contínua em Instituições de Educação Superior (IES) e cursos. Diante disso, é necessária uma reflexão contínua para o aprimoramento e o desenvolvimento dos sistemas de avaliação e acreditação, de modo que, como defende Malavasi (2013), não sejam meros produtores de retratos ou verificadores de conformidade, mas que contribuam para melhoria das políticas públicas em educação.

As avaliações externas são necessárias e importantes, mas "não podem sufocar as práticas de diálogo e questionamentos próprios da avaliação institucional participativa que fazem das instituições espaços públicos de debates e reflexões", como lembra Dias Sobrinho (2008, p.823). Vale ressaltar ainda, que a crescente mercantilização, diversificação de oferta, internacionalização e a necessidade de mobilidade profissional, impulsionadas especialmente pelo imperativo tecnológico vigente, reforçam o importante papel da avaliação e da acreditação, para garantir uma formação de qualidade e que contribua para os desenvolvimentos local e regional. 
Desta forma, o objetivo deste artigo é analisar as principais características dos sistemas de avaliação e acreditação da educação superior presentes em países da América Latina e Caribe. O estudo examina a configuração de cada sistema, seus instrumentos de avaliação institucional e de cursos de graduação, na modalidade presencial, vigentes em cada país. Dentre os aspectos abordados, estão: a maturidade do sistema; valorização do contexto institucional e da autoavaliação; e subsídio às políticas públicas.

\section{Metodologia}

Para a composição do estudo foi realizada uma pesquisa bibliográfica e documental, que utilizou como principais referências os documentos, legislações e informações disponibilizados pelos organismos oficiais responsáveis pela avaliação e acreditação de cada país e, adicionalmente, quando necessário, o apoio dos autores que estudaram essas realidades. Considerando-se a abrangência que envolve a América Latina e o Caribe, optou-se por escolher países anteriormente estudados por Dias Sobrinho (2006), Bermheim (2008) e Lemaitre (2018), ou seja, Brasil, Colômbia, México, Peru, Venezuela, Equador, Chile e Uruguai, além de Argentina, Costa Rica, Paraguai, Bolívia, sendo que os quatro últimos não serão tratados neste artigo, uma vez que não tiveram respondentes na pesquisa de campo.

Complementando a pesquisa bibliográfica, buscou-se investigar as percepções de professores e pesquisadores em atividade em cada país, por meio de uma pesquisa de campo, cujo acesso aos pesquisados foi feito aleatoriamente, adotando-se o critério de acessibilidade, ou seja, de acordo com a possibilidade de acesso que o pesquisador tem aos sujeitos, como define Vergara (2005). Para convidar os participantes, foram utilizadas as redes de contatos: da Red de Investigación Estudios Organizacionales en América Latina, el Caribe e Iberoamérica (REOALCEI), do Centro de Investigaciones Internacionales (CIN-SAS) e contatos pessoais do pesquisador.

Antes da aplicação dos questionários o projeto de pesquisa foi aprovado em âmbito internacional pela REOALCEI e em âmbito nacional pelo Comitê da Ética e Pesquisa (CEP) da Universidade Estadual de Campinas (UNICAMP). A coleta das informações ocorreu de 13/01/2019 a 01/04/2019 em âmbito internacional e de 18/03/2019 a 01/04/2019 em âmbito nacional.

Para a coleta das informações, foram elaborados dois questionários, um em português e outro em espanhol, estruturados e com o mesmo teor, disponibilizados online, utilizando-se da ferramenta de formulários do Google. Os questionários foram estruturados em 7 partes, buscando-se melhor agrupamento das questões e facilidade aos respondentes. A primeira parte contém a explicação da pesquisa e o Termo de Consentimento Livre e Esclarecido (TCLE), a segunda e quarta apresentam blocos de questões fechadas, a terceira apresenta bloco de questões com escala Likert, a quinta contém os dados relativos à caracterização do participante, a sexta traz questões específicas para aqueles que se declaram avaliadores e a última apresenta uma questão aberta para considerações e a solicitação do endereço eletrônico, para o caso do participante ter interesse nos resultados da pesquisa.

\begin{tabular}{l|l|l|l|l|l} 
(c) Rev. Inter. Educ. Sup. & Campinas, SP & v.6 & $1-31$ & $\mathrm{e} 020043$ & 2020
\end{tabular}


$\mathrm{Na}$ análise das respostas das questões fechadas e dos dados relativos à caracterização da amostra, foram usadas escalas nominais, que segundo Marconi e Lakatos (2002), visam a transformar fatos qualitativos em quantitativos ou variáveis para serem mensuradas, no caso da escala nominal em categorias específicas, o que permite analisar percentualmente os agrupados em cada categoria.

Nas questões com escala Likert, em que o respondente escolhe de 1 a 5, de acordo com seu grau de concordância com a afirmação, as respostas são analisadas mediante índices de concordância e discordância, em que o Índice de Concordância (IC) considera apenas as respostas 4 e 5, enquanto o Índice de Discordância (ID) considera apenas as respostas 1 e 2, desconsiderando assim as respostas indiferentes (3). Desta forma, é possível comparar os dois grupos de respondentes e realizar as inferências.

Para analisar as respostas das questões abertas, foi utilizada a técnica de análise de conteúdo, que segundo Levin e Fox (2004) permite ao pesquisador descrever objetivamente o conteúdo das mensagens coletadas. Nesta, o conteúdo das mensagens coletadas é agrupado em unidades de análise e eixos temáticos, que Franco (2008) chama de categorias e núcleos de sentido. Esse procedimento ajuda a compreender o significado dado pelo respondente e a comparar com outras respostas, permitindo atingir a essência do conteúdo, visando responder ao questionamento da pesquisa. Os agrupamentos permitem ainda, analisar quantitativamente a frequência com que determinado termo aparece e quais aparecem mais ou menos.

Nas análises estatísticas, utilizou-se o software IBM SPSS Statistics v.25, a confiabilidade do instrumento, nas questões com escala Likert foi testada, com base na amostra e obteve-se o coeficiente alfa de Cronbach de 0,815 , o que indica de acordo com Malhotra (2008), uma alta confiabilidade, sendo a amostra válida e sem viés. Aplicou-se ainda, o teste do qui-quadrado para verificar, segundo Larson e Faber (2010), se uma distribuição de frequência se encaixa em uma distribuição esperada e obteve-se como resultado que 11 das 13 questões testadas, apresentam distribuição compatível com o esperado, ou seja, as respostas ocorrem com probabilidades iguais. Nas questões em que isso não ocorreu, relativas ao tipo de IES do pesquisado (pública ou privada) e à percepção quanto nível de maturidade do sistema de avaliação e acreditação, não inviabilizaram as análises propostas, uma vez que são analisadas de forma integrada com as demais respostas.

\section{Agências e Organismos de Avaliação e Acreditação na América Latina e Caribe}

Na América Latina e Caribe, há uma extensa diversidade de modelos de avaliação e acreditação, sendo que quase todos os países ou em alguns casos sub-regiões criaram seus organismos de acreditação a partir da década de 1990, de acordo com Dias Sobrinho (2006). Apesar disso, observa-se que foram nos anos 2000, que grande parte dos organismos, se estruturou e sedimentou sua atuação. 
Na maioria dos países, os organismos responsáveis por estes processos são estatais, mas há também agências da sociedade e instâncias internacionais, em alguns casos. Mesmo ocorrendo de forma diferente nos países, os processos de forma geral, seguem os padrões de qualidade estabelecidos pelos organismos reguladores, que normalmente consideram a autoavaliação e a avaliação externa realizada por equipe de pares avaliadores. A avaliação de cursos acontece em todos os países, porém, a avaliação institucional não ocorre da mesma forma.

Brasil

As primeiras experiências envolvendo a avaliação da educação superior brasileira, remontam à década de 1970, envolvendo cursos e programas de pós-graduação. Ao longo das décadas seguintes outras iniciativas surgiram e auxiliaram nas discussões que culminaram em 14 de abril de 2004, com a Lei No. 10.861, que instituiu o Sistema Nacional de Avaliação da Educação Superior (SINAES), com o objetivo de "assegurar o processo nacional de avaliação das instituições de Educação Superior, dos cursos de graduação e do desempenho acadêmico de seus estudantes" (BRASIL, 2004) e definiu o Instituto Nacional de Estudos e Pesquisas Educacionais Anísio Teixeira (INEP) como responsável pela realização das avaliações.

O SINAES assenta-se sobre três pilares fundamentais: 1) Avaliação das instituições; 2) Avaliação dos cursos e 3) Avaliação dos Estudantes; sendo que as duas primeiras se dão por meio de avaliações in loco, com base em instrumentos de avaliação padronizados e realizada por equipe de especialistas vinculados ao Banco de Avaliadores (BASIS) e a avaliação dos estudantes ocorre anualmente, por áreas do conhecimento, de acordo com calendário trienal por meio da aplicação do Exame Nacional de Desempenho dos Estudantes (ENADE). Toda a tramitação dos processos de avaliação é feita no Sistema e-MEC, exclusivamente de forma eletrônica, o que permite transparência e segurança.

Os instrumentos de avaliação institucional (INEP, 2017a; INEP, 2017b) estão estruturados em cinco eixos: planejamento e avaliação institucional; desenvolvimento institucional; políticas acadêmicas; políticas de gestão; e infraestrutura. Os instrumentos de avaliação de cursos (INEP, 2017c; INEP, 2017d) estão estruturados em três dimensões: organização didático-pedagógica; corpo docente e tutorial; e infraestrutura.

Com base nos resultados das avaliações in loco, são gerados o Conceito de Curso (CC) e o Conceito Institucional (CI). Enquanto que, com base nos resultados do ENADE, nas informações do Censo da Educação Superior e nos conceitos da pós-graduação stricto sensu, quando aplicáveis, são gerados quatro indicadores de qualidade: o Índice Geral de Cursos (IGC); o Conceito Preliminar de Curso (CPC); o Conceito ENADE e o Índice de Diferença entre os Desempenhos Observado e Esperado (IDD). Todos esses indicadores de qualidade são apresentados em uma escala de 1 a 5 , em que os conceitos abaixo de 3 , são considerados insatisfatórios e podem implicar medidas para IES ou curso, com a previsão de punições que vão desde a suspenção da entrada de novos estudantes, bloquear o acesso dos estudantes aos financiamentos públicos e até mesmo ao fechamento do curso ou IES. Esses indicadores são 
disponibilizados periodicamente, de acordo com o ciclo avaliativo, em área pública e de livre acesso do sistema e-MEC.

De acordo com Weko (2017) nenhum país membro da OCDE implementa avaliações públicas, externas, obrigatórias e padronizadas de estudantes do ensino superior, assim, neste aspecto a experiência brasileira do ENADE foi inovadora mundialmente. Apesar disso, o ENADE, dentro do SINAES, tem sido usado de forma desproporcional, o que leva o sistema como um todo a minorar o valor da avaliação externa por pares. Não há uma adequada valorização da relevância e inserção social da IES, que são reduzidas a apenas um indicador no instrumento de avaliação. A autoavaliação, apesar de obrigatória e considerada no processo, normalmente como uma exigência meramente burocrática, aquém de poder contribuir para a melhoria da qualidade.

A partir de 2017, esses instrumentos passaram por reformulação, que trouxeram em seu bojo os objetivos de estimular iniciativas educacionais e melhorar o processo de ensino e aprendizagem, destacando-se a ênfase em práticas inovadoras e exitosas, bem como, a utilização de ferramentas de gestão e acompanhamento de planos de ações, valorizando a utilização da tecnologia da informação. Porém, muitos dos critérios de análise, antes quantitativos deram lugar a critérios qualitativos, deixando margem de interpretação e entendimento por parte do avaliador, o que levou a um cenário de insegurança para as IES e um sensação de subjetividade para o avaliador. Desde a mudança de governo em 2019, têm ocorrido sucessivas trocas nos comandos do MEC e do INEP, que trazem insegurança acerca das políticas a serem adotadas.

\section{Colômbia}

O Sistema Nacional de Acreditação (SNA) foi criado na Colômbia, pela Lei N ${ }^{\circ}$. 30, de 28 de dezembro de 1992, com as diretrizes definidas em seus artigos 53 ao 56 e tem como objetivo "garantir à sociedade que as instituições que fazem parte do Sistema cumpram os mais elevados requisitos de qualidade e que atendam aos seus propósitos e objetivos" (COLOMBIA, 1992, tradução nossa), a lei criou o Conselho Nacional de Acreditação (CNA) e estabelece sua relação com o Conselho Nacional de Educação Superior (CESU).

São características marcantes do sistema colombiano, reforçadas nas diretrizes de avaliação institucional (CNA, 2014) e nas diretrizes de avaliação de cursos (CNA, 2013), a busca pela alta qualidade, o caráter voluntário de participação das IES e a ênfase na autoavaliação institucional, como uma tarefa permanente das IES e ponto de partida do processo de acreditação.

A acreditação institucional, de acordo com CNA (2014), envolve um exame abrangente de toda a organização, distribuídos em doze fatores: missão e o projeto institucional; estudantes; professores; processos acadêmicos; visibilidade nacional e internacional; pesquisa e criação artística; relevância e o impacto social; processos de autoavaliação e autorregulação; bem-estar institucional; organização, gestão e administração; recursos de apoio acadêmico e infraestrutura física; e recursos financeiros.

\begin{tabular}{l|c|c|c|c|c} 
(c) Rev. Inter. Educ. Sup. & Campinas, SP & v.6 & $1-31$ & $\mathrm{e} 020043$ & 2020 \\
\hline
\end{tabular}


A acreditação de cursos, de acordo com CNA (2013), considera dez fatores: missão e o projeto institucional e de curso; estudantes; professores; processos acadêmicos; visibilidade nacional e internacional; pesquisa, inovação e criação artística e cultural; bem-estar institucional; organização, administração e gestão; impacto dos egressos no meio; e recursos físicos e financeiros.

Semelhante ao ENADE brasileiro, a Colômbia aplica dois exames aos estudantes: o SaberPro e o SaberTyt, sendo o primeiro voltado aos cursos de formação universitária profissional e o segundo aos cursos técnico profissionais e tecnológicos, ambos conduzidos pelo Instituto Colombiano de Fomento a Educação Superior (ICFES). O SaberPro é aplicado aos estudantes que concluíram pelo menos $75 \%$ de seus créditos, enquanto o SaberTyT é aplicado aos estudantes próximos a graduar-se ou graduados (ICFES, 2019). Esses exames são aplicados para a maioria dos cursos e são obrigatórios como comprovante de grau acadêmico e para o exercício profissional, independentemente da aprovação ou não do estudante. Diferentemente do ENADE, não há uma vinculação direta dos resultados desses exames com o processo de acreditação, porém, é necessário que a IES realize uma análise desses resultados, crie planos de ação e demonstre os resultados das ações no processo, estimulando assim, a melhoria contínua.

O SNA colombiano tem como pontos positivos a valorização da autoavaliação, da relevância e do impacto social na avaliação institucional, bem como, o impacto dos egressos em sua realidade. Em julho de 2019, com a publicação do Decreto Lei No. 1.330, houve mudanças na Educação Superior do país e apesar de não ter sido possível analisar os impactos desse decreto, observa-se que as expectativas são positivas, conforme repercutiu El Meridiano (2019), indicando que pode haver uma valorização ainda maior da identidade, da vocação institucional e de seu contexto, assim como, a incorporação de aspectos relacionados à empregabilidade e aos resultados da aprendizagem como indicadores de qualidade. Em se materializando essas promessas, o sistema colombiano dá um passo importante no sentido da garantia da qualidade.

\section{México}

A partir da década de 1990 a avaliação da educação superior ganha relevância no México por meio de ações e políticas, voltadas à avaliação de instituições, cursos, professores e ao aprendizado dos estudantes são propostas, de acordo com Narro, Martuscelli e Barzana (2012). Neste período, os seguintes organismos são estabelecidos: os Comitês Interinstitucionais de Avaliação das Instituições de Educação Superior (CIEES), o Centro Nacional de Avaliação para a Educação Superior (CENEVAL), o Conselho para a Acreditação da Educação Superior (COPAES) e a Comissão Nacional de Avaliação da Educação Superior (CONAEVA), todos relacionados à promover um processo de avaliação nacional, estabelecer critérios e políticas gerais para a melhoria das condições de cursos e instituições de educação superior. 
O COPAES é uma associação civil sem fins lucrativos que atua como a única instância autorizada pelo Governo Federal mexicano, ligada à Secretaria da Educação Pública (SEP), para conferir reconhecimento formal e supervisionar os Organismos Acreditadores (OA). Entre 2000 e 2010, o COPAES operou sob a estrutura dos CIEES, posteriormente, houve a separação dos organismos, a fim de articular o trabalho das diferentes instâncias de avaliação e acreditação, contando hoje com 30 OA reconhecidos (COPAES, 2019). O estabelecimento do COPAES como instância adicional, se deu, de acordo com Dias Sobrinho (2006), devido à proliferação dos OA.

Não há no país, um organismo oficial acreditador de IES, equivalente a uma acreditação institucional. Porém, de acordo com Espinosa (2013), há experiências significativas neste sentido, que são conduzidas pela Associação Nacional Universidades e Instituições de Educação Superior (ANUIES) e pela Federação das Instituições Mexicanas de Educação Superior (FIMPES), que estabelecem processos próprios de acreditação. Enquanto no processo da FIMPES, que atua apenas no segmento de IES privadas, a adesão é facultativa, no caso da ANUIES, que atua majoritariamente com IES públicas, o processo é obrigatório para se associar. Ambas, estabelecem a autoavaliação e a visita de pares avaliadores para concessão ou renovação da acreditação.

A acreditação de cursos, fica a cargo dos CIEES, que se configuram como uma associação civil sem fins lucrativos e contam com nove Comitês Interinstitucionais (CI), sendo sete de cursos e dois de gestão educacional. Os CIEES (2018a) adotam como metodologia a acreditação por módulos ou funções, de acordo com o tipo de instituição, ao todo são seis módulos: gestão institucional (básico), gestão da pesquisa, gestão da inovação, gestão da vinculação, internacionalização e gestão da difusão da cultura.

O instrumento de acreditação de cursos (CIEES, 2018b), conta com doze categorias de análise: objetivos do curso; condições gerais de funcionamento do curso; modelo educacional e currículo; atividades para a formação integral; processo de ingresso no curso; trajetória acadêmica; egresso do curso; resultados dos alunos; resultados do curso; pessoal acadêmico; infraestrutura acadêmica e serviços de apoio. A categoria resultado dos alunos, foi introduzida em 2016 e leva em consideração os resultados dos alunos em exames de egressos externos à instituição, como por exemplo, o Exame Geral para o Egresso de Licenciatura (EGEL) aplicado pelo CENEVAL, de acordo com a adesão da IES, como também as certificações de competências outorgadas por organismos externos, dentre outros.

O sistema de acreditação mexicano demonstra certa complexidade, devido à sua estrutura e variedade de organismos acreditadores. Seu desafio está em equilibrar a liberalidade dada às IES e aos organismos acreditadores ao longo do tempo, mantendo o atendimento à diversidade de tipos de instituições e organizações acadêmicas. A fragmentação em módulos do processo de acreditação, assim como, a existência de mecanismos não oficiais de acreditação institucional, distintos para IES públicas e privadas, podem propiciar à sociedade a sensação de um simulacro de qualidade. 
O Sistema Nacional de Avaliação, Acreditação e Certificação da Qualidade Educacional (SINEACE) foi criado pela Lei No 28.740, de 23 de maio de 2006, com o objetivo de "garantir os níveis básicos de qualidade que devem ser fornecidos pelas Instituições referidas na Lei Geral de Educação No. 28.044, e promover seu desenvolvimento qualitativo" (PERU, 2006, tradução nossa).

O processo de acreditação é voluntário, com exceção dos cursos das áreas de educação e saúde, realizado por seis organismos acreditadores credenciados no âmbito do sistema. Para as avaliações são disponibilizados três documentos orientadores ou modelos de acreditação: para cursos de institutos e escolas de educação superior; para cursos universitários de educação superior; e para a acreditação institucional de universidades (SINEACE, 2019).

O instrumento para acreditação institucional de universidades (SINEACE, 2017) engloba as dimensões: gestão estratégica, gestão institucional, apoio institucional e resultados. São avaliados onze fatores de análise: planejamento institucional; posicionamento; gestão da qualidade; formação integral; pesquisa aplicada, desenvolvimento tecnológico e inovação; responsabilidade social; gestão docente; recursos humanos e financeiros; bem-estar institucional; infraestrutura e informação; e resultados de impacto na sociedade.

Os instrumentos de acreditação de cursos (SINEACE, 2016a; SINEACE, 2016b) preveem quatro dimensões: gestão estratégica, formação integral, apoio institucional e resultados. As dimensões consideram doze fatores de análise: planejamento do curso; gestão do perfil do egresso; garantia da qualidade; processo de ensino e aprendizagem; gestão dos professores; apoio aos estudantes; pesquisa aplicada, desenvolvimento tecnológico e inovação; responsabilidade social; serviços de bem-estar; infraestrutura e suporte; recursos humanos; e resultados relativos ao perfil do egresso. Sendo que este último, não considera resultados de exames, não previstos no SINEACE, mas o acompanhamento durante todo o processo formativo e indicadores relativos à inserção do mercado de trabalho, dentre outros.

Os documentos orientadores (SINEACE, 2016a; SINEACE, 2016b; SINEACE, 2017) demonstram explicitamente uma preocupação em manter uma coerência com modelos internacionais e cita especificamente Colômbia e Chile. Percebe-se, nos fatores de análise uma valorização da autoavaliação e do contexto da IES, este último enfatizado nos fatores de posicionamento e resultados dos impactos na sociedade. Apresenta como desafio a expansão da acreditação institucional para institutos e escolas de educação superior.

\section{Venezuela}

O Comitê de Avaliação e Acreditação de Cursos e Instituições de Educação Superior (CEAPIES) foi criado pela Lei $N^{\circ} 39.032$ de 07 de outubro de 2008, como sendo um órgão do Ministério do Poder Popular para a Educação Universitária (MPPEU) e tendo como objetivo coordenar os processos de avaliação e acreditação institucional, de cursos e 
programas, assim como, garantir, reconhecer e promover a qualidade da educação superior (ARCU-SUL, 2019).

Diferentemente dos demais países estudados, em que, foram utilizadas as fontes oficiais e governamentais, no caso da Venezuela, isso não foi possível, uma vez que os sites desses órgãos estão fechados para acesso de fora do país. Não se constatou a existência de um processo equivalente à avaliação institucional, de acordo com Lemaitre (2018), o MPPEU apenas outorga o credenciamento para IES e caberia à Oficina de Planejamento do Setor Universitário (OPSU) a implementação de um programa de avaliação institucional, sendo que hoje apenas exerce a função de administrar o sistema nacional de ingresso. Complementa, ainda, que o sistema de avaliação e acreditação venezuelano, assim como, seu ordenamento legal, encontram-se em processo de reestruturação.

\section{Equador}

As funções de avaliação e acreditação no Equador foram definidas na Lei Orgânica de Educação Superior (LOES) de 6 de outubro de 2010, porém, apenas em 2013, efetivou-se o Conselho de Avaliação, Acreditação e Garantia da Qualidade da Educação Superior (CEAACES), rebatizado posteriormente, de Conselho de Garantia da Qualidade da Educação Superior (CACES), que se apresenta como um órgão técnico, público e autônomo, encarregado de planejar, coordenar e executar as políticas de avaliação, acreditação e garantia da qualidade das IES e cursos de graduação e pós-graduação, além realizar exames de habilitação profissional (CACES, 2019a).

A acreditação institucional é obrigatória e aplicada às universidades e escolas politécnicas que compõem o sistema de educação superior equatoriano, tendo como objetivo determinar o grau de cumprimento dos padrões de qualidade definidos no modelo vigente. As instituições que tiverem resultados satisfatórios nas avaliações recebem a acreditação por cinco anos, de acordo com quatro categorias: A, B, C e D, sendo que as IES da categoria D são aquelas que ainda se encontram em processo de acreditação e tem um prazo para se adequarem, caso não cumpram passam a figurar no grupo de instituições não acreditadas (CACES, 2019a).

As diretrizes para a acreditação institucional (CACES, 2019b) preveem quatro eixos fundamentais da IES a serem avaliados: ensino, pesquisa, vinculação com a sociedade e condições institucionais. Dentro desses eixos são considerados itens como: corpo docente, corpo discente, produção acadêmica e científica, infraestrutura e gestão. Em cada um dos eixos são consideradas três dimensões: planejamento, execução e resultados. Os indicadores recebem conceitos: não cumprimento, cumprimento insuficiente, cumprimento parcial, aproximação de cumprimento, cumprimento satisfatório.

Com o objetivo de verificar os propósitos futuros da IES e promover a melhoria contínua em médio e longo prazo, de acordo com CACES (2019b), as novas diretrizes publicadas em 2019, foram acrescidas de sete indicadores denominados de projetivos e sem 
fins de acreditação: internacionalização; inovação; uso social do conhecimento; bem-estar universitário; inclusão e equidade; interculturalidade; e sustentabilidade ambiental, que podem fazer parte da acreditação a partir de 2026.

O processo de avaliação de cursos de graduação consiste em duas etapas: a avaliação do ambiente de aprendizagem, em que são consideradas as condições de oferta do curso; e os resultados da aprendizagem, por meio do Exame Nacional de Avaliação de Cursos, aplicado aos alunos do último ano do curso. O resultado das duas etapas determina a acreditação ou não de um curso, culminando na divulgação pública dos resultados. Este processo se aplica apenas aos cursos considerados de interesse público: Medicina, Odontologia, Enfermagem e Direito, cada um com um modelo específico de avaliação, não existindo previsão de avaliação dos demais cursos. Para esses cursos o processo é obrigatório e em caso de não acreditação haverá a suspensão do curso, sendo vedados novos ingressos durante o período de dez anos.

O sistema de avaliação e acreditação equatoriano se apresenta bem estruturado, especialmente no âmbito da avaliação institucional, cujo instrumento passou por mudanças e traz características inovadoras. O contexto institucional, denominado de vinculação com a sociedade é muito valorizado e teve seu peso aumentado na avaliação institucional a partir de 2015 de acordo com CACES (2019b). O desafio do país está em expandir a acreditação de cursos, para além dos quatro obrigatórios.

\section{Chile}

O marco legal da avaliação e acreditação no Chile foi a promulgação da Lei No. 20.129, de 17 de Novembro de 2006 (CHILE, 2006), que estabeleceu o Sistema Nacional de Garantia da Qualidade da Educação Superior, integrado pelo Ministério da Educação, o Conselho Nacional de Educação, pela Superintendência de Educação Superior e pela Comissão Nacional de Acreditação (CNA-CHILE), a qual cabe a definição das diretrizes para a acreditação institucional, de cursos de graduação e pós-graduação.

$\mathrm{Na}$ acreditação institucional, de acordo com o documento orientador da CNA-CHILE (2014), são avaliados os seguintes aspectos: missão e propósitos; políticas e mecanismos de garantia da qualidade; condições de operação e resultados; e capacidade de ajuste (melhoria contínua).

A acreditação de cursos de graduação é feita pelas agências autorizadas pela CNACHILE, que atualmente são sete. Sendo de caráter voluntário, exceto para os cursos de Medicina, Odontologia e Formação de Professores, de acordo com a CNA-CHILE (2019). Os critérios para acreditação de cursos de graduação estão definidos em resolução da CNACHILE (2015), que considera doze critérios: propósitos; integridade; perfil do egresso; currículo; vinculação com o meio; organização e administração; corpo docente; infraestrutura e recursos de aprendizagem; participação e bem-estar estudantil; criação e pesquisa do corpo docente; efetividade e resultado do processo formativo; e autorregulação e melhoria contínua. No caso do resultado do processo formativo, não são previstos exames aos estudantes, são avaliados aspectos relativos ao percurso formativo, evasão, dentre outros.

\begin{tabular}{l|c|c|c|c|c} 
C) Rev. Inter. Educ. Sup. & Campinas, SP & v.6 & $1-31$ & $\mathrm{e} 020043$ & 2020 \\
\hline
\end{tabular}


As diretrizes de acreditação demonstram valorização da autoavaliação, bem como, valorização do contexto institucional. Os resultados das avaliações, bem como, as informações gerais de IES e cursos, são transparentes e divulgadas de forma pública.

\section{Uruguai}

O Uruguai é o único país da América Latina que não possui um sistema de avaliação e acreditação da educação superior institucionalizado. O Ministério da Educação e Cultura realiza a autorização para o funcionamento de IES e cursos. Para representar o país no Sistema ARCU-SUL e administrar as diretrizes do sistema em seu território, o Decreto $\mathrm{N}^{\circ}$. 251/008, de 19 de maio de 2008, criou a Comissão Ad Hoc de Acreditação, com independência técnica no âmbito do Ministério da Educação e Cultura (ARCU-SUL, 2019).

Em julho de 2019, um anteprojeto de lei foi encaminhado ao parlamento para a criação do Instituto Nacional de Acreditação e Avaliação da Educação Superior (INAEET), fruto das discussões de um grupo de trabalho, conduzido pela Comissão Ah hoc de Acreditação, conforme informações veiculadas pelo MEC-UY (2019) e pela La Diaria (2019).

\section{Resultados}

Ao todo foram coletadas 124 respostas de 8 países, a Figura 1 a seguir apresenta o mapa de distribuição dos respondentes. 
Figura 1. Mapa de distribuição dos respondentes

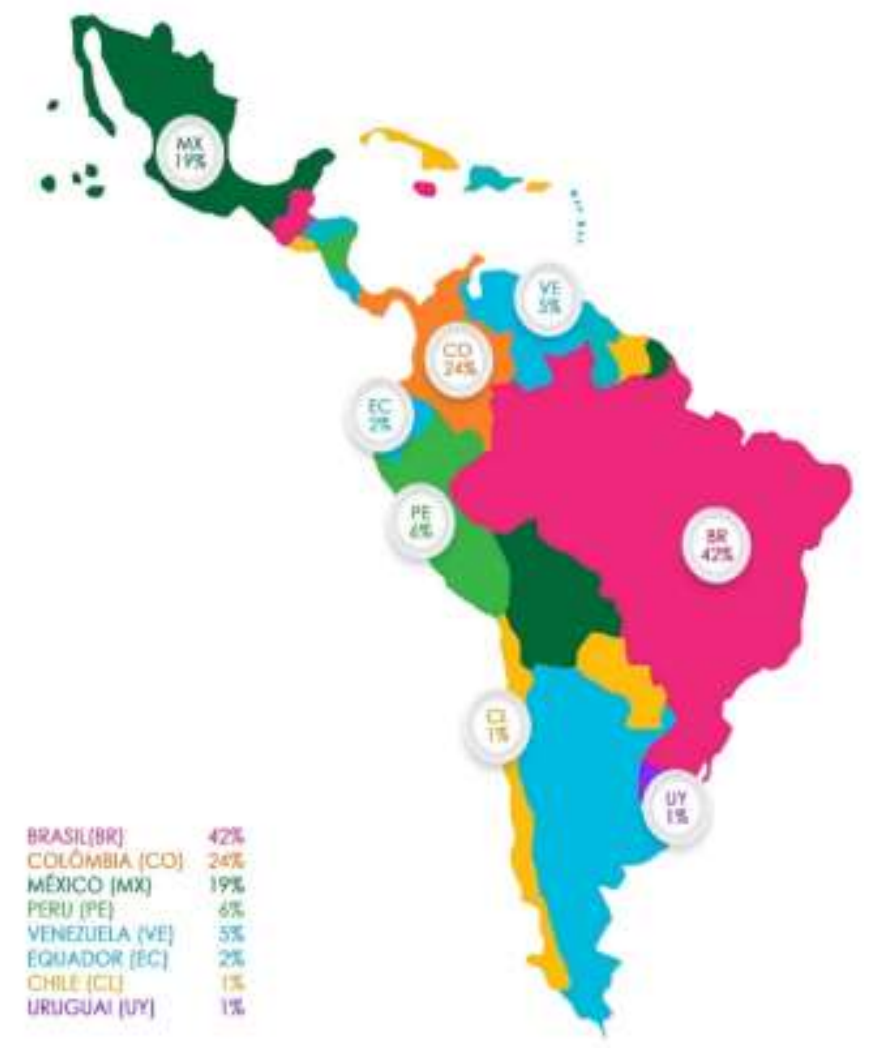

Fonte: os autores (2019).

Considerando a natureza qualitativa do estudo, bem como, a grande dificuldade para obter respondentes qualificados e aderentes à proposta da pesquisa em âmbito internacional, as respostas de todos os países foram consideradas nas análises, contudo, importante salientar que Chile e Uruguai, apresentaram apenas um respondente cada e desta forma, não é possível generalizar as percepções obtidas nessas localidades.

A Tabela 1, a seguir, apresenta as maiores ocorrências das características que compõem o perfil dos respondentes. 
Tabela 1. Perfil dos Respondentes

\begin{tabular}{llcc}
\hline & \multicolumn{3}{c}{ Respondente } \\
Característica & Resposta & s & \% \\
& & N=124 \\
\hline Atuação em IES & Privada & 64 & 51 \\
& Pública & 60 & 49 \\
Atua como Avaliador & Sim & 53 & 43 \\
& Não & 71 & 57 \\
Atividade Ensino e Pesquisa & & 94 & 76 \\
Atividade Gestão & & 69 & 56 \\
\hline
\end{tabular}

Fonte: os autores (2019).

As informações indicam uma alta qualificação dos respondentes e aderência à proposta da pesquisa, considerando que boa parte atua como avaliador, assim como, desenvolvem além das atividades de ensino e pesquisa, atividades de gestão em cargos de coordenação, direção e pró-reitoria.

Dentre aqueles que atuam como avaliadores, 91\% atuam há 4 anos ou mais, e $79 \%$ mais de 5 anos nesta atividade, denotando relevante experiência em avaliação. Considerando o vínculo com os organismos de acreditação, em que um mesmo avaliador pode estar vinculado a mais de um organismo, tem-se que 58\% estão vinculados ao INEP/MEC - Brasil, 14\% ao CNA - Colômbia, $14 \%$ ao sistema ARCU-SUL, $11 \%$ a organismos do México e 5\% ao SINEACE - Peru. Ressalta-se que, aqueles vinculados ao Sistema ARCU-SUL, também estão vinculados ao INEP/MEC, assim como, a presença de respondentes vinculados a mais de um organismo mexicano, contribui para o enriquecimento das análises.

A presença de um contingente importante dos respondentes com experiência em avaliação e ligados a agências locais e internacionais de acreditação, traz importante contribuição para a pesquisa uma vez que este público conhece em detalhes os processos de acreditação e os marcos regulatórios, têm a vivência de ambos os lados, avaliador e avaliado, bem como, uma visão críticas dos aspectos envolvidos nesses sistemas e podem colaborar com subsídios para sua melhoria.

Iniciando-se a análise das respostas relativas aos sistemas de avaliação e acreditação, a primeira questão solicitava ao respondente que marcasse as palavras que melhor definissem o sistema de seu país, podendo escolher no mínimo 3 das 15 disponíveis. Ao todo foram escolhidas 413 palavras, uma média de 3,3 por respondente, a Tabela 2 a seguir, apresenta a distribuição. 
Tabela 2. Definição Sistemas de Avaliação e Acreditação

\begin{tabular}{lcc}
\hline Palavras & Respostas & \% \\
& $\mathbf{N}=\mathbf{4 1 3}$ & \\
\hline Qualidade & 63 & 15 \\
Regulação & 61 & 15 \\
Certificador & 43 & 10 \\
Supervisão & 40 & 10 \\
Controle & 35 & 8 \\
Formação & 28 & 7 \\
Padronizado & 27 & 7 \\
Fiscalizador & 23 & 6 \\
Ranking & 22 & 5 \\
Internacionalização & 19 & 5 \\
Burocrático & 18 & 2 \\
Mercado & 11 & 3 \\
Confiável & 9 & 2 \\
Informativo & 7 & 2 \\
Punitivo & 7 & 2 \\
\hline & & 5 \\
\hline
\end{tabular}

Fonte: os autores (2019).

As principais escolhas dos respondentes (qualidade, regulação, certificador e supervisão) estão aderentes à dinâmica de funcionamento e aos objetivos da maioria dos sistemas de avaliação e acreditação estudados, que normalmente contém menção à garantia de qualidade da educação superior como se pode observar: "O SINAES tem por finalidade a melhoria da qualidade da educação superior" (BRASIL, 2004), "garantir à sociedade que as instituições que fazem parte do Sistema cumpram os mais elevados requisitos de qualidade" (COLOMBIA, 1992, tradução nossa) e "estabelecer os critérios, padrões e processos de avaliação, acreditação e certificação, a fim de garantir os níveis de qualidade básica que deve ser fornecida pelas Instituições" (PERU, 2006, tradução nossa). As respostas relativas ao caráter certificador são mais evidentes na Colômbia, México e Peru, e os termos regulação e supervisão, ocorrem mais no Brasil, ainda que também apareçam em menor evidência em todos os países. 
Com relação às palavras menos mencionadas (confiável, informativo e punitivo), por um lado, pode-se entender que esses atributos não definiriam diretamente os sistemas de avaliação e acreditação. Por outro, as respostas podem levar a crer há falta de transparência, indicando falta de confiabilidade e informação. O caráter punitivo não ter sido atribuído aos sistemas pode ser considerado natural, uma vez que, com exceção de Brasil e Equador, em que há punição prevista, nos demais isso não ocorre.

Na questão que trata da maturidade dos sistemas de avaliação e acreditação, foi solicitado aos respondentes que escolhessem uma das opções para classificar o sistema: Inicial - ainda incipiente e em construção; Executado - atende as exigências burocráticas; Definido - está sistematizado e implementado; Gerenciado - produz indicadores qualitativos; Otimizado - utiliza indicadores para melhora da qualidade e das políticas. A Tabela 3, a seguir, apresenta os resultados obtidos.

Tabela 3. Maturidade dos Sistemas de Avaliação e Acreditação

\begin{tabular}{lccccccccc}
\hline Maturidade & Total & Brasil & Colômbia & México & Peru & Venezuela & Equador & Chile Uruguai \\
\hline Inicial & 18 & 8 & 3 & 2 & 2 & $\mathbf{2}$ & & $\mathbf{1}$ \\
Executado & $\mathbf{3 3}$ & $\mathbf{1 4}$ & 5 & $\mathbf{8}$ & 1 & $\mathbf{2}$ & $\mathbf{2}$ & $\mathbf{1}$ \\
Definido & $\mathbf{3 0}$ & $\mathbf{1 5}$ & $\mathbf{8}$ & 2 & $\mathbf{3}$ & 1 & 1 & \\
Gerenciado & 20 & 9 & 5 & 5 & 1 & & & \\
Otimizado & 23 & 6 & $\mathbf{9}$ & $\mathbf{6}$ & 1 & 1 & & \\
\hline
\end{tabular}

Fonte: os autores (2019).

$\mathrm{Na}$ análise geral, observa-se que a maior parte das respostas está entre Executado e Definido, padrão mantido nas respostas brasileiras, com uma leve oscilação no sentido de otimizado na Colômbia e uma discrepância nas respostas do México que fica com maiores ocorrências em executado e otimizado. Os documentos oficiais e os indícios apresentados por Lemaitre (2018), mostram que os sistemas Uruguaio e Venezuelano estariam em fase inicial, enquanto México, Peru, Equador e Chile, podem ser considerados como definidos e Brasil e Colômbia, como gerenciados. Desta forma, verifica-se que em geral, os respondentes têm normalmente uma percepção aquém do esperado, acerca da maturidade de seus sistemas, o que possibilita propostas de melhorias e evolução dos mesmos.

As percepções dos respondentes quanto a atuação dos avaliadores, é apresentada na Tabela 4, a seguir. 
Tabela 4. Atuação dos Avaliadores

\begin{tabular}{lcccccccc}
\hline Respostas & Total & Brasil Colômbia & México & Peru & Venezuela & Equador & Chile Uruguai \\
\hline $\begin{array}{l}\text { Falta capacitação } \\
\text { para os } \\
\text { avaliadores }\end{array}$ & 32 & 8 & 6 & 8 & $\mathbf{4}$ & $\mathbf{4}$ & $\mathbf{1}$ & $\mathbf{1}$ \\
$\begin{array}{l}\text { Nem sempre } \\
\text { cumprem de } \\
\text { forma isenta seu } \\
\text { papel }\end{array}$ & 35 & $\mathbf{2 6}$ & 6 & 2 & 1 & & \\
$\begin{array}{l}\text { São capacitados e } \\
\text { cumprem de } \\
\text { forma isenta seu } \\
\text { papel }\end{array}$ & $\mathbf{5 7}$ & 18 & $\mathbf{1 8}$ & $\mathbf{1 3}$ & 3 & 2 & $\mathbf{3}$ & \\
\hline
\end{tabular}

Fonte: os autores (2019).

Apesar de que na amostra geral 46\% dos respondentes entenderem que há capacitação e isenção na atuação dos avaliadores, 54\% divergem, $28 \%$ apontando a questão ética como ponto de atenção e $26 \%$ a questão da capacitação. Nota-se que no Brasil, $50 \%$ dos respondentes apontam para uma preocupação quanto a isenção na atuação dos avaliadores. Nas respostas abertas, foi possível verificar que isso está relacionado em grande parte a uma possível atuação inadequada, na percepção dos respondentes, de avaliadores oriundos de IES públicas nas IES privadas. A preocupação quanto a capacitação é mais latente no Peru, Venezuela, Chile e Uruguai, que se justifica, com exceção do Chile, pelo fato dos sistemas estarem em fase inicial ou em consolidação, como apontado na Tabela 3.

A composição das comissões de avaliação externa por pares avaliadores está presente em grande parte dos países estudados, de acordo com as informações de seus organismos. Cada um, porém, utiliza critérios específicos para a seleção, formação da comissão e de seu banco de avaliadores. No México, especificamente, que utiliza o formato de avaliação interinstitucional, a comissão é composta por pares avaliadores da própria IES, no Brasil, as comissões são compostas de forma aleatória, havendo restrição quanto a atuação do avaliador no estado onde atua.

Quanto ao alinhamento dos sistemas de avaliação e acreditação com os organismos internacionais, obteve-se que $80 \%$ dos pesquisados tem a percepção de que os sistemas de avaliação e acreditação estão alinhados às diretrizes dos organismos internacionais, ocorrendo em todos os países pesquisados, sendo que $70 \%$ entende, ainda, que os sistemas de avaliação e acreditação conserva suas características locais e regionais.

Com exceção do Uruguai, que não possui um sistema estabelecido, todos os demais países estão em linha com o esperado pela OCDE (2008) e pelo BM (1995), no sentido de desenvolver uma cultura de qualidade na educação superior e assegurar mecanismos de 
avaliação, porém, no que se refere à produção de informações transparentes à sociedade e que auxiliem as IES em sua melhoria, Brasil, Colômbia e Chile, já tem caminhado neste sentido, enquanto os demais ainda não.

No que tange à relação dos sistemas de avaliação e acreditação com as políticas públicas, cerca de $30 \%$ dos pesquisados acreditam que os sistemas de avaliação e acreditação subsidiam com informações, mas não influenciam diretamente as políticas públicas de seu país, número superior ainda, para os respondentes brasileiros $(44 \%)$, venezuelanos $(50 \%)$ e equatorianos (67\%). Para os colombianos (36\%) e peruanos (37\%) seus sistemas de acreditação influenciam nas políticas de expansão da educação superior, enquanto no México as respostas se concentraram em: influencia no contingenciamento de recursos para educação pública $(30 \%)$ e não influencia $(30 \%)$.

Nas realidades brasileira e colombiana, os resultados das avaliações influenciam as políticas de expansão da educação superior. No Brasil, a Portaria MEC No. 11 de 20 de junho de 2017, atrela o Conceito Institucional (CI) à quantidade de polos de educação a distância que uma IES pode abrir por ano, assim como, a Portaria MEC No. 20 de 21 de dezembro de 2017, condiciona o aumento de vagas ao CI. Enquanto, de forma parecida, na Colômbia, o Decreto No. 1.330 de 25 de julho de 2019, permite às IES acreditadas e com cursos acreditados, que ofertem estes cursos em qualquer parte do território nacional sem a necessidade de visita de avaliação, facilitando o processo de expansão. Nos demais países não se verificou explicitamente nenhuma vinculação dos sistemas de acreditação com a adoção de políticas públicas.

A Tabela 5, a seguir, apresenta uma síntese dos resultados gerais acerca da percepção dos respondentes acerca de diversos aspectos que envolvem os sistemas de avaliação e acreditação. Nestas questões, o respondente deveria, em uma escala de 1 a 5, escolher em que grau concorda ou não com cada afirmação, lembrando que, o Índice de Concordância (IC) considera apenas as respostas 4 e 5, assim como, o Índice de Discordância (ID) considera apenas as respostas 1 e 2 , desconsiderando assim as respostas indiferentes (3). 
Tabela 5. Percepções Gerais acerca dos Sistemas de Avaliação e Acreditação

\begin{tabular}{|c|c|c|c|c|c|c|c|}
\hline Afirmações / Respostas (N=124) & 1 & 2 & 3 & 4 & 5 & IC & ID \\
\hline $\begin{array}{l}\text { O Sistema de Avaliação da Educação Superior } \\
\text { presente em meu país cumpre sua finalidade. }\end{array}$ & 6 & 20 & 29 & 57 & 12 & $56 \%$ & $21 \%$ \\
\hline $\begin{array}{l}\text { O Sistema de Avaliação da Educação Superior } \\
\text { presente em meu país avalia da mesma forma } \\
\text { Instituições de Educação Superior Públicas e Privadas. }\end{array}$ & 16 & 33 & 16 & 37 & 22 & $48 \%$ & $40 \%$ \\
\hline $\begin{array}{l}\text { A autoavaliação é relevante no Sistema de Avaliação } \\
\text { da Educação Superior presente em meu país. }\end{array}$ & 5 & 14 & 26 & 53 & 26 & $64 \%$ & $15 \%$ \\
\hline $\begin{array}{l}\text { O contexto local e regional de atuação das Instituições } \\
\text { de Educação Superior, bem como sua relevância, é } \\
\text { valorizado nos processos de avaliação. }\end{array}$ & 6 & 23 & 31 & 54 & 10 & $52 \%$ & $23 \%$ \\
\hline $\begin{array}{l}\text { O Sistema de Avaliação da Educação Superior } \\
\text { presente em meu país avalia da mesma forma, ou seja, } \\
\text { de maneira padronizada todos os tipos de curso. }\end{array}$ & 11 & 19 & 22 & 51 & 21 & $\mathbf{5 8 \%}$ & $24 \%$ \\
\hline $\begin{array}{l}\text { As visitas in loco dos avaliadores ocorrem com } \\
\text { periodicidade adequada e atendem à proposta do } \\
\text { sistema. }\end{array}$ & 5 & 25 & 24 & 56 & 14 & $56 \%$ & $24 \%$ \\
\hline
\end{tabular}

Fonte: os autores (2019).

1- Discordo Totalmente; 2-Discordo; 3-Indiferente; 4-Concordo; 5-Concordo Totalmente.

Dentre as afirmações apresentadas, com exceção da segunda, acerca o mesmo tratamento dado dentro do sistema de avaliação e acreditação, às instituições públicas e privadas, as demais respostas apresentam alto IC, sempre com percentuais acima do dobro do ID. O que indica que para a maioria dos respondentes, na amostra geral, os sistemas de avaliação e acreditação, cumprem sua finalidade, consideram a autoavaliação e o contexto local de forma relevante, avaliando de forma padronizada os cursos e as visitas externas atendem seus objetivos, porém, esse consenso não ocorre na análise de cada país.

Com relação ao cumprimento da finalidade dos sistemas de avaliação e acreditação, há uma maior discordância do que concordância nos respondentes de Venezuela e Uruguai, em linha com a percepção sobre a baixa maturidade dos sistemas nestes países, retratada na Tabela 3, e com o fato de estarem estruturando seus sistemas.

$\mathrm{Na}$ percepção quanto ao tratamento igualitário nas avaliações de IES públicas e privadas em seus sistemas, as respostas de Chile, México e Venezuela, apresentam altos ID, $100 \%$, 48\% e $67 \%$, respectivamente, indicando uma percepção de tratamento diferenciado das IES nessas realidades. No sistema mexicano, a resposta está condizente com a realidade, 
uma vez que não há um processo de acreditação institucional oficial, mas são feitos por entidades que reúnem diferentes tipos de IES, uma majoritariamente para públicas e outra para privadas.

Nos demais países, não há evidência dessa distinção, porém, isso pode estar relacionado a dois fatores: 1) grande parte dos sistemas de avaliação e acreditação terem se originado em universidades públicas e trazerem em seu bojo, indicadores e critérios próprios dessa realidade, que posteriormente foram impostos à realidade das privadas; 2) é comum em vários países a predominância de membros oriundos de IES públicas em Conselhos, Comitês e demais órgãos dos sistemas de avaliação e acreditação, bem como, em seu próprio banco de avaliadores. Ambos fatores, podem trazer a sensação de desfavorecimento de um tipo de IES em relação a outro. Nos comentários, que serão analisados posteriormente, fica evidente essa percepção por boa parte dos respondentes, de vários dos países estudados.

A autoavaliação é percebida como relevante no âmbito dos sistemas de avaliação em todos os países, exceto na resposta do Chile. Com base nos documentos analisados de cada um dos países, assim como, no fluxo do processo de avalição e no peso da autoavaliação, pode-se dizer que esta é muito relevante na Colômbia, México, Peru e Equador. No Chile pode-se observar sua relevância maior na avaliação institucional, enquanto no Brasil, comparativamente aos países mencionados, apesar de considerada no processo não apresenta peso considerável na composição dos conceitos, o que minora sua importância.

A relevância e valorização do contexto regional nos processos de avaliação não é percebida pelos respondentes de Chile e Uruguai, que discordaram da afirmação. Nos demais países houve sempre IC acima de $33 \%$ até $61 \%$, destacando Brasil com maior número de discordantes, ID 31\%. A análise dos instrumentos de avaliação e critérios de qualidade de cada sistema, permite afirmar que todos consideram o contexto institucional em seus processos, porém, é dada uma ênfase maior no Peru e no Equador. No Brasil, apesar do contexto ser considerado no processo, este não apresenta peso considerável na composição dos conceitos. Ressalta-se, ainda, que diferente de outros países, o instrumento de avaliação institucional avalia de forma padronizada Faculdades, Centros Universitários e Universidades, com alguns poucos indicadores específicos, que são insuficientes para considerar a vocação institucional da IES e seu impacto local.

Quanto ao processo de avaliação de forma padronizada e ocorrendo da mesma forma para todos os cursos, há discordância apenas no respondente do Chile, já que nas respostas de México e Peru, há ID de $30 \%$ e $38 \%$, respectivamente. A análise dos documentos de avaliação de cursos de cada país, mostrou que apesar de critérios comuns serem adotados, não há uma padronização no México, Equador e Chile. No México, isso ocorre devido à diversidade de organismos de acreditação e normalmente especializados em áreas do conhecimento, que definem seus próprios processos e indicadores, enquanto no Chile, há diretrizes gerais, mas são os organismos que definem como o curso é avaliado, e no Equador há um instrumento para cada curso. 
Com relação à periodicidade das visitas in loco dos avaliadores, apenas Equador não apresenta uma resposta conclusiva, tendo ID e IC iguais, chama a atenção também que o México apresenta o maior ID (35\%). Nas informações disponibilizadas, pelos organismos de avaliação e acreditação, não foi possível evidenciar qualquer tipo de distorção em relação às visitas atenderem às propostas dos seus sistemas. Especificamente, no Brasil e na Colômbia, há previsão de dispensa de visitas em determinadas situações, o que pode ser questionável uma vez que a visita in loco é importante componente do sistema e sua ocorrência periódica contribui para que a IES busque melhoria contínua.

Para complementar as informações obtidas nas respostas fechadas, foram examinadas as respostas das questões abertas, que foram deixadas por 72 dos 124 respondentes, destas, 10 respostas foram desconsideradas para análise por se tratar de conteúdos neutros, ou seja, trazem mensagens fora do contexto da pesquisa. Assim, 62 respostas tiveram seu conteúdo analisado, com respondentes de seis países: Brasil (35\%); Colômbia (29\%); México (18\%); Peru (10\%); Venezuela (5\%) e Equador (3\%), destacando-se que no caso do Peru, $75 \%$ dos respondentes daquele país também deixaram suas considerações em respostas abertas, indicado um interesse sobre o tema.

Por meio da análise dos conteúdos, partindo-se das 62 repostas, chegou-se a 97 unidades de análise, que foram agrupadas em 33 eixos temáticos, a Tabela 6 a seguir, apresenta os cinco eixos com maior número de respostas.

Tabela 6. Eixos Temáticos

\section{Unidades de Análise}

Subjetividade, falta de clareza, padronização, rigidez, indicadores

Melhoria do processo, considerar aspectos qualitativos, considerar resultados

Sistema consolidado, sistema adequado, relevância e importância do sistema

Alinhamento com organismos regionais, valorizar aspectos de internacionalização, convalidação de títulos

Capacitação dos avaliadores, capacitação IES e envolvidos com avaliação
Eixo Temático

\section{Ocorrências}

\section{Instrumento de}

Avaliação

Necessidade de

evolução

Maturidade do Sistema

Internacionalização

7

Capacitação

6

Fonte: os autores (2019). 
O eixo temático mais presente está relacionado aos instrumentos de avaliação e foi mencionado por 10 respondentes brasileiros e 3 colombianos. Os comentários dos brasileiros versaram sobre a subjetividade do instrumento de avaliação, como ilustra a resposta a seguir.

Acredito que o instrumento de avaliação ainda contém um caráter subjetivo, em alguns indicadores, dando margem a entendimentos e análises divergentes; o que faz com que os profissionais que atuam nas avaliações discutam alguns aspectos e que seja necessário um senso comum entre eles (respondente [28]).

Os comentários dos colombianos sobre o tema se referiram à rigidez do instrumento como mostra a resposta: "Os indicadores de medição padronizados são importantes para o monitoramento da qualidade, no entanto, esses aspectos têm desviado o interesse das instituições para o cumprimento de indicadores (criando um sistema rígido de controle sobre a qualidade) e pouco flexíveis para se adaptar a novas áreas de interesse público" (respondente [38], tradução nossa). Bem como, sugestão para inclusão de indicadores que valorizem a pesquisa e a relação com as empresas.

O segundo eixo temático mais comentado está relacionado à necessidade de evolução dos sistemas de avaliação e acreditação, este anseio foi percebido nos respondentes de todos os países que deixaram seus comentários. É necessário, segundo os respondentes, que os sistemas deixem de ser meramente burocráticos, de verificação de indicadores, de conformidade ou não conformidade, e passem a trazer uma contribuição efetiva para a qualidade, de forma propositiva para a melhoria contínua. Assim como, é preciso que o processo de avaliação evolua para além de análises documentais e realize a análise de resultados, considerando inclusive, formas distintas de avaliação qualitativa e quantitativa.

As respostas a seguir ilustram parte desses anseios de evolução: "O sistema do meu país requer estudos e análises que visem elevar o nível de maturidade com o objetivo de fornecer suporte aos avaliadores para que sua função não se limite apenas a fiscalização e controle" (respondente[55], tradução nossa) e "utilizar modelos multivariados para avaliar as múltiplas dimensões da percepção da qualidade educacional e contrastar esses resultados com indicadores objetivos "(respondente[62], tradução nossa).

No eixo relacionado à maturidade dos sistemas de avaliação e acreditação, as respostas vieram de Brasil, Colômbia e Venezuela. Enquanto os comentários de Brasil e Colômbia apresentaram conteúdo enfatizando a consolidação de seus sistemas, os da Venezuela enfatizam a necessidade de criação e implantação de um sistema para o país, em linha com o que fora apresentado na Tabela 3.

Verifica-se que os aspectos de internacionalização são uma preocupação em todos os países que responderam, exceto Peru, com mais ênfase em Colômbia e México, o comentário a seguir sintetiza essa preocupação: “É necessário primeiro ter um modelo adequado de acordo com as exigências da Educação Superior na América Latina, para que se possa competir globalmente" (respondente [65], tradução nossa). 
Com relação à capacitação, as respostas vieram de Brasil, Peru e Venezuela. No Brasil os aspectos éticos estão mais presentes nos comentários, enquanto no Peru, percebe-se inclusive, o anseio de capacitação para funcionários e outros envolvidos com a avaliação. Tanto no Peru como na Venezuela, percebeu-se que a necessidade de capacitação advém do desconhecimento do sistema e de estarem ainda, em sua fase inicial.

Além dos eixos apresentados, surgiram ainda outros, com pelo menos cinco respostas, que convém abordar, como no caso do Brasil, em que houve contundente crítica à gestão do INEP, inclusive com termos mais fortes e até pejorativos, como bagunça, confusão, momento confuso e falta de transparência, houve ainda, uma cobrança para que haja envolvimento e participação dos avaliadores na revisão e elaboração dos instrumentos.

A necessidade de considerar o contexto onde a IES atua é uma preocupação no Brasil, Colômbia e México, de acordo com os comentários a seguir: "É necessário desenvolver novas políticas públicas para avaliar as universidades públicas e privadas de acordo com o contexto de cada região. (respondente [76], tradução nossa), "O Sistema não leva em consideração as diferenças regionais" (respondente [42]) e "Se deve considerar o contexto onde a instituição universitária está localizada" (respondente [68], tradução nossa). Essa percepção complementa e reforça o que fora apresentado nas análises, de cada país, consolidado na Tabela 5.

Os aspectos relacionados à burocracia dos sistemas foram mencionados por respondentes da Colômbia, Equador e México. Os pontos comentados se relacionam com o processo formal dos sistemas, com exigências muitas vezes desnecessárias para cumprimento de diretrizes, assim como, críticas aos valores cobrados e à existência de um mercado apenas certificador, não interessado na qualidade, mas no atendimento de conformidade. São feitas ainda, menções à baixa remuneração dos avaliadores e ao caráter arrecadatório dos sistemas.

Além dos pontos abordados, cabe um destaque específico à realidade mexicana, onde o atual modelo que prevê sistemas distintos de avaliação e acreditação, com diversos organismos, trouxe a percepção, por parte dos respondentes, de que falta uma integração e ao mesmo tempo a definição de critérios e requisitos mínimos para a avaliação. Os comentários a seguir ilustram bem essa situação.

No México, existem dois sistemas de avaliação e acreditação do ES. Um como muito definido para instituições públicas em que instituições privadas encontram muitas dificuldades para atender a alguns dos critérios estabelecidos. Outro em que apenas instituições privadas participam. Talvez um dia ambos os sistemas sejam homologados. (respondente [119], tradução nossa)

1.- Estabelecer um acordo sobre uma estratégia nacional e um marco regulatório mínimo para a avaliação e acreditação de instituições de educação superior e cursos. 2.- Consolidar um sistema de informação ao alcance de todas as instituições onde são registrados avanços na construção do Sistema. (respondente [81], tradução nossa).

A análise das respostas abertas contribuiu para elucidar e reforçar alguns pontos levantados nas questões fechadas, bem como, entender mais profundamente as percepções 
dos respondentes acerca de suas realidades. Mesmo que parte dos respondentes tenha considerado os sistemas adequados ou até consolidados, a necessidade de evolução ficou patente em todos os países analisados. Notou-se um anseio no sentido de que os sistemas avancem para que haja uma contribuição efetiva para a melhoria da qualidade, por meio de formatos multivariados de avaliações que incluam aspectos qualitativos, que valorizem os resultados das ações e o impacto local das IES e cursos.

\section{Considerações Finais}

Dentro do contexto da América Latina e Caribe, foram apresentadas e analisadas informações acerca da avaliação e acreditação da educação superior em oito países, consolidando tanto as informações obtidas nos organismos oficiais de avaliação e acreditação, como as percepções colhidas dos docentes e pesquisadores em atividades nessas localidades. Considerando a amplitude do estudo, convém lembrar que há aspectos que podem ser aprofundados e futuramente discutidos, a seguir são destacados os principais achados da pesquisa.

Apesar de existir certa diversidade nos modelos e configurações dos sistemas de avaliação e acreditação estudados, observa-se que, de forma geral, seus processos envolvem: um momento de avaliação interna, a autoavaliação; a avaliação externa realizada in loco por uma comissão de pares avaliadores; a emissão dos pareceres ou atos de credenciamento; e em casos específicos a aplicação de exames aos estudantes. É importante destacar que o Brasil é o único país que aplica exames em larga escala aos egressos de cursos superiores e cujos resultados estão diretamente ligados ao processo de avaliação dos mesmos. Em outros países, quando há a aplicação de exames aos egressos, isso ocorre em alguns cursos e normalmente está relacionado ao exercício profissional, não estando condicionado ao processo de avaliação e acreditação, exceto no caso do Equador, em que o resultado do desempenho do estudante é parte do processo. Destaca-se que há um movimento na Colômbia, com as mudanças em seu sistema introduzidas em 2019, no sentido de se utilizar os exames já existentes para fins de acreditação.

Com relação aos organismos responsáveis pelo processo de avaliação e acreditação, existem aqueles mantidos pelo Estado, como no caso de Brasil, Colômbia e Equador, e aqueles realizados por agências credenciadas da sociedade, supervisionadas pelo Estado, como ocorre no México, Peru e Chile. Com exceção do Brasil e Equador, em que o processo de avaliação e acreditação institucional é obrigatório, em todos os demais a acreditação é voluntária, lembrando ainda que, o México não possui organismo acreditador de IES. No caso das avaliações de cursos, em geral a acreditação é obrigatória para aqueles considerados de interesse público, normalmente das áreas da saúde, educação, direito, dentre outros. O Brasil é o único país que tem avaliação obrigatória de todos os cursos, assim, verifica-se que há um grande desafio aos demais países para que haja um aumento na adesão aos processos de acreditação de cursos e também institucional. 
Nas realidades estudadas, exceto a Venezuela e o Uruguai, verificou-se que os sistemas de avaliação e acreditação se encontram minimamente definidos e estruturados, considerando que Brasil e Colômbia, já estariam mais maduros. As mudanças mais recentes nos marcos legais da avaliação e acreditação, ocorridas a partir de 2016 no México e Peru, 2017 no Brasil e 2019 no Chile, Colômbia, Equador e Uruguai, indicam a preocupação desses países em aprimorar seus sistemas de avaliação e acreditação. Apesar disso, convém destacar que Brasil, Chile e México apresentam certa estagnação e as mudanças promovidas não se refletiram, ainda, em melhoria da qualidade, ao passo que Peru e Equador, mesmo tendo sistemas mais novos, apresentam, juntamente com a Colômbia, modelos substancialmente promissores, com grande valorização da autoavaliação e do contexto institucional.

Em se tratando os sistemas de avaliação e acreditação da educação superior, como indutores de políticas públicas de melhoria da educação, não apenas em seu nível, mas que reflete também nos demais níveis educacionais, salta aos olhos a constatação de que, em todas as realidades estudadas, não se evidenciou uma conexão relevante entre os sistemas de avaliação e acreditação com as políticas públicas para a educação em seus países. Mesmo nos casos de Brasil e Colômbia, em que as avaliações são utilizadas nas políticas de expansão da educação superior, verifica-se que se tratam apenas de mecanismos reguladores de oferta.

Observando as características marcantes de cada sistema, são apresentadas a seguir algumas sugestões, recomendações e reflexões, com vistas ao aprimoramento desses sistemas em suas realidades. Para que o SINAES brasileiro possa figurar na vanguarda dos sistemas de avaliação, como outrora, é imperativo que o ENADE seja repensado enquanto exame e principalmente em relação ao seu peso em detrimento aos demais componentes do processo avaliativo. É preciso avaliar adequadamente Faculdades, Centros Universitários e Universidades, de forma própria, como já é feito em outros países e valorizar sua inserção local. Aos instrumentos, agregar um rol de evidências em cada indicador, trará mais transparência e minimizará a atual sensação de subjetividade.

Embora não tenha feito parte do escopo deste trabalho analisar as mudanças sucedidas nos sistemas colombiano e chileno, em 2019, entende-se ser aconselhável no caso da Colômbia, se precaver ao introduzir em seu processo de acreditação, os resultados dos exames em larga escala aplicados aos estudantes, para não repetir os desvios ocorridos como no caso do Brasil com o ENADE, especialmente no que diz respeito à valorização desses exames, uma vez que, eles facilmente podem desfavorecer os demais aspectos do processo avaliativo. No caso do Chile, é recomendável uma reflexão acerca de seus instrumentos de avaliação, de modo a aprimorar a forma como os resultados são considerados em cada indicador, alinhado com o que já existe em outros países.

A estrutura complexa do sistema de acreditação mexicano, calcada no atendimento à diversidade de suas instituições e cursos, com seus diversos organismos de acreditação, tem se mostrado ineficiente para garantir minimamente a qualidade ofertada por suas IES e cursos. É mandatório que seja estruturado um processo oficial e coordenado de acreditação institucional, como também, que seja realizada a consolidação das informações sobre a

\begin{tabular}{l|l|l|l|l|l} 
(C) Rev. Inter. Educ. Sup. & Campinas, SP & v.6 & $1-31$ & e020043 & 2020
\end{tabular}


acreditação de IES e cursos, em um sistema único que disponibilize de forma transparente essas informações à sociedade. Cabe ainda, uma análise dos atuais organismos acreditadores e o estímulo para que haja o estabelecimento de diretrizes comuns, maior coordenação e cooperação entre eles, para que possam, em conjunto, promover mudanças que reflitam em melhoria da qualidade das avaliações nacionais.

Os sistemas de acreditação de Equador e Peru, apresentam bases sólidas, com boas perspectivas futuras e uma visão de melhoria contínua, destacando-se especialmente os instrumentos de avaliação equatorianos que apresentam diferenciais dentre todos os estudados. Ambos têm o desafio de expandir sua abrangência, no caso do sistema peruano, ampliar a acreditação institucional para outros tipos de IES, além das universidades; e no caso do sistema equatoriano, levar a acreditação de cursos para além dos quatro obrigatórios.

Ao Uruguai cabe a missão de implantar seu sistema nacional de acreditação e tirar o incômodo de ser o único país da América Latina que não possui um sistema de acreditação. Enquanto à Venezuela, a despeito de todas suas dificuldades, cabe levar a cabo o plano de reestruturação de seu sistema de acreditação para que possa, inclusive, recuperar o prestígio de seus cursos e instituições.

Em maior ou menor grau, há uma necessidade premente de que os sistemas avancem no sentido da busca pela garantia e melhoria da qualidade da formação na educação superior em suas localidades. É preciso superar os aspectos burocráticos, de verificação de conformidade, de atribuição pura e simples de conceito, desenvolvendo-se avaliações formativas, que valorizem a autoavaliação, levando em conta o contexto e a pertinência locais. Assim como, os impactos, os resultados e a transformação que as IES e os cursos provocam em suas realidades, de forma a alimentar uma cultura de qualidade e melhoria contínua, que abandone a ideia de classificação, exclusão e submissão a um sistema meritocrático injusto que premia alguns e condena outros. Ao contrário, que as avaliações sejam justificadas por buscarem alimentar políticas públicas nacionais que induzam ações de formação ampla do estudante, do cidadão pleno e de construção de uma sociedade mais igualitária e justa.

\section{Referências}

ARCU-SUL. Sistema de Acreditação de Cursos Universitários do MERCOSUL. Site Institucional. 2019. Disponível em: http://edu.mercosur.int/arcusur/index.php/pt-br/ Acesso: 16.jan.2019.

BANCO MUNDIAL (BM). La Enseñanza Superior: las lecciones derivadas de la experiencia (El Desarrollo en la práctica). Washington, D.C.: BIRD / Banco Mundial, 1995.

BERNHEIM, Carlos T. La calidad de la educación superior y su acreditación: la experiencia centroamericana. Revista da Avaliação da Educação Superior. Sorocaba, vol. 13, núm. 2, p. 313-336, junho, 2008.

\begin{tabular}{l|l|l|l|l|l} 
(C) Rev. Inter. Educ. Sup. & Campinas, SP & v.6 & $1-31$ & $\mathrm{e} 020043$ & 2020 \\
\hline
\end{tabular}


BRASIL. Decreto No. 9.235, de 15 de dezembro de 2017. Diário Oficial [da] República Federativa do Brasil, Poder Executivo, Brasília, DF, 18 dez. 2017.

BRASIL. Lei No. 10.861, de 14 de abril de 2004. Diário Oficial [da] República Federativa do Brasil, Poder Executivo, Brasília, DF, 15 abr. 2004.

CONSEJO DE ASEGURAMIENTO DE LA CALIDAD DE LA EDUCACIÓN SUPERIOR (CACES). Site Institucional. 2019a.Disponível em:

https://www.caces.gob.ec/web/ceaaces/inicio Acesso: 12.mar.2019.

CONSEJO DE ASEGURAMIENTO DE LA CALIDAD DE LA EDUCACIÓN SUPERIOR (CACES). Modelo de Evaluación Externa de Universidades y Escuelas Politécnicas. Jun. 2019b.

CARVALHO, Alexey. La influencia de la globalización en la Educación Superior Brasileña. In: II Encuentro Internacional de Investigadores y Estudiantes de REOALCEI, 2018, Santa Marta, Colombia: Universidad del Magdalena, 2018.

CHILE. Ley 20.129 de 17 de noviembre del 2006. Establece un Sistema Nacional de Aseguramiento de la Calidad de la Educación Superior. Santiago, 17 dec. 2006.

COLOMBIA. Ley 30 de 28 de diciembre de 1992. por el cual se organiza el servicio público de la Educación Superior. Bogotá-DC, 28 dec. 1992.

COLOMBIA. Decreto 1330 del 25 de julio de 2019. Bogotá-DC, 25 jul. 2019.

COMISIÓN NACIONAL DE ACREDITACIÓN (CNA-CHILE). Site Institucional. 2019.

Disponível em: https://www.cnachile.cl Acesso: 07.jan.2019.

COMISIÓN NACIONAL DE ACREDITACIÓN (CNA-CHILE). Operacionalización de las Pautas Evaluación para la Acreditación Institucional. Santiago, 2014. Disponível em:https://www.cnachile.cl/Documentos\%20de\%20Paginas/OPERACIONALIZACION_081 02014.pdf Acesso: 07.jan.2019.

COMISIÓN NACIONAL DE ACREDITACIÓN (CNA-CHILE). Resolución Exenta No. DJ-009-04. Santiago, 3.ago.2015. Disponível em:

https://www.cnachile.cl/Criterios\%20y\%20Procedimientos/DJ\%20009-4\%20Criterios.pdf Acesso: 07.jan.2019.

COMITÉS INTERINSTITUCIONALES PARA LA EVALUACIÓN DE LA EDUCACIÓN SUPERIOR (CIEES). Proceso general para la evaluación de instituciones de educación superior. México, 2018a.

COMITÉS INTERINSTITUCIONALES PARA LA EVALUACIÓN DE LA EDUCACIÓN SUPERIOR (CIEES). Proceso general para la evaluación de programas educativos de educación superior. México, $2018 \mathrm{~b}$. 
CONSEJO NACIONAL DE ACREDITACIÓN (CNA). Lineamentos para la acreditación de programas de pregrado. Bogotá-DC, enero. 2013.

CONSEJO NACIONAL DE ACREDITACIÓN (CNA). Acuerdo 03 de 2014. por el cual se aprueban los Lineamentos para la Acreditación Institucional. Bogotá-DC, 16.dec. 2014.

CONSEJO PARA LA ACREDITACIÓN DE LA EDUCACIÓN SUPERIOR (COPAES).

Sítio Institucional. 2019. Disponível em: https://www.copaes.org Acesso em: 06.jan.2019.

DIAS SOBRINHO, José. Acreditación de la educación superior en América Latina y el Caribe. In: GUNI, Global University for Innovation. La Educación Superior en el Mundo 2007. Acreditación para la garantía de la calidad ¿qué está en juego? Madrid: Ediciones Mundi-Prensa, 2006. p.282-295.

DIAS SOBRINHO, José. Qualidade, Avaliação: do SINAES a Índices. Avaliação. Sorocaba. v. 13 , n. 3, pp. 817-825, nov. 2008.

EL MERIDIANO. La nueva coordenada de las universidades. 18.ago.2019. Disponível em: https://elmeridiano.co/noticia/la-nueva-coordenada-de-las-universidades Acesso: 27.ago.2019.

ESPINOSA, Angélica B. Genealogía de la evaluación y acreditación de instituciones en México. Perfiles Educativos. México, v. 35, n. especial, p.17-32, 2013.

FRANCO, Maria L. P. B. Análise de conteúdo. 3.ed. Brasília: Líber Livro Editora, 2008.

ICFES. Instituto Colombiano de Fomento de la Educación Superior. Site Institucional. 2019. Disponível em: http://www2.icfes.gov.co/ Acesso: 25.jan.2019.

INSTITUTO NACIONAL DE ESTUDOS E PESQUISAS EDUCACIONAIS ANÍSIO TEIXEIRA (INEP). Instrumento de Avaliação Institucional Externa Presencial e a Distância - Credenciamento. Brasília-DF: INEP, 2017a.

INSTITUTO NACIONAL DE ESTUDOS E PESQUISAS EDUCACIONAIS ANÍSIO TEIXEIRA (INEP). Instrumento de Avaliação Institucional Externa Presencial e a Distância - Recredenciamento. Brasília-DF: INEP, 2017b.

INSTITUTO NACIONAL DE ESTUDOS E PESQUISAS EDUCACIONAIS ANÍSIO TEIXEIRA (INEP). Instrumento de Avaliação de Cursos de Graduação Presencial e a Distância - Autorização. Brasilia-DF: INEP, 2017c.

LA DIARIA. Ejecutivo propone crear Instituto de Acreditación de Educación Terciaria. 23.jul.2019. Disponível em: https://educacion.ladiaria.com.uy/articulo/2019/7/ejecutivopropone-crear-instituto-de-acreditacion-de-educacion-terciaria/ Acesso: 06.ago.2019.

LARSON, Ron; FABER, Betsy. Estatística Aplicada. São Paulo: Pearson Prentice Hall, 2010. 
LEMAITRE, María José (coord). La educación superior como parte del sistema educativo de América Latina y el Caribe. Calidad y aseguramiento de la calidad. Córdoba:

Universidad Nacional de Córdoba, 2018.

LEVIN, Jack; FOX, James A. Estatística para ciências humanas. 9.ed. São Paulo: Prentice Hall, 2004.

MALAVASI, Maria M. S. Avaliação é boa foto, mas deve resultar em políticas públicas. O Estado de São Paulo. 13 dez. 2013. Disponível em: http://saopaulo.estadao.com.br/noticias/geral,avaliacao-e-boa-foto-mas-deve-resultar-em-politicaspublicas-imp-,1103533 Acesso: 04.jan.2019.

MARCONI, Marina de A.; LAKATOS, Eva Maria. Técnicas de pesquisa. 5.ed. São Paulo: Atlas, 2002.

MINISTÉRIO DA EDUCAÇÃO (MEC). Portaria Normativa No. 11, de 20 de junho de 2017. Diário Oficial [da] República Federativa do Brasil, Poder Executivo, Brasília, DF, 21 jun. 2017a.

MINISTÉRIO DA EDUCAÇÃO (MEC). Portaria Normativa No. 20, de 21 de dezembro de 2017. Diário Oficial [da] República Federativa do Brasil, Poder Executivo, Brasília, DF, 22 dez. $2017 b$.

MINISTÉRIO DA EDUCAÇÃO (MEC). Portaria Normativa No. 21, de 21 de dezembro de 2017. Diário Oficial [da] República Federativa do Brasil, Poder Executivo, Brasília, DF, 22 dez. 2017 c.

MINISTERIO DE EDUCACIÓN Y CULTURA (MEC-UY). Site Institucional. Uruguai, 2019. Disponível em: https://mec.gub.uy Acesso: 6.ago.2019.

NARRO Robles, José; MARTUSCELLI Quintana, Jaime y BARZANA García, Eduardo (Coord.). Plan de diez años para desarrollar el Sistema Educativo Nacional. México: UNAM, 2012. Disponível em: http://www.planeducativonacional.unam.mx Acesso: 6.jan. 2019 .

ORGANIZAÇÃO PARA A COOPERAÇÃO E DESENVOLVIMENTO ECONÔMICO (OCDE). Tertiary Education for the Knowledge Society. Paris: OECD, 2008.

PERU. Ley 28.740 de 23 de mayo del 2006. Ley del Sistema Nacional de Evaluación, Acreditación y Certificación de la Calidad Educativa. Lima, 23 may. 2006.

RED IBEROAMERICANA PARA EL ASEGURAMIENTO DE LA CALIDAD EN LA EDUCACIÓN SUPERIOR (RIACES). Glosario Internacional RIACES de Evaluación de la Calidad y Acreditación. RIACES, 2004.

SISTEMA NACIONAL DE EVALUACIÓN, ACREDITACIÓN Y CERTIFICACIÓN DE LA CALIDAD EDUCATIVA (SINEACE). Site Institucional. 2019. Disponível em: https://www.sineace.gob.pe/ Acesso: 25.fev.2019.

\begin{tabular}{l|c|c|c|c|c} 
(c) Rev. Inter. Educ. Sup. & Campinas, SP & v.6 & $1-31$ & $\mathrm{e} 020043$ & 2020
\end{tabular}


SISTEMA NACIONAL DE EVALUACIÓN, ACREDITACIÓN Y CERTIFICACIÓN DE LA CALIDAD EDUCATIVA (SINEACE). Nuevo Modelo de Acreditación - Institutos y Escuelas de Educación Superior. 2016a.

SISTEMA NACIONAL DE EVALUACIÓN, ACREDITACIÓN Y CERTIFICACIÓN DE LA CALIDAD EDUCATIVA (SINEACE). Modelo de Acreditación para Programas de Estudios de Educación Superior Universitaria. 2016b.

SISTEMA NACIONAL DE EVALUACIÓN, ACREDITACIÓN Y CERTIFICACIÓN DE LA CALIDAD EDUCATIVA (SINEACE). Modelo de Acreditación Institucional para Universidades. 2017.

VERGARA, Sylvia C. Projetos e relatórios de pesquisa em administração. 6.ed. São Paulo: Atlas, 2005.

WEKO, Thomas. Medidas de Qualidade do Ensino Superior: qual o papel da avaliação dos estudantes em países da OCDE? In: Seminário Internacional - Avaliação da Educação Superior. Brasília: INEP, 2017. 